Journal of Humanities and Social Sciences Studies (JHSSS)

ISSN: $2663-7197$

DOI: 10.32996/jhsss

Journal Homepage: www.al-kindipublisher.com/index.php/jhsss

\title{
Women During General Community Quarantine (GCQ): A Case Study
}

\author{
Pearl Lettee D. Maunes \\ PhD student, University of Southeastern Mindanao, College Faculty, University of Mindanao Digos, Digos City, Philippines
}

$\square$ Corresponding Author: Pearl Lettee D. Maunes, E-mail: pldmaunes@yahoo.com, Orcid ID: https://orcid.org/00000001-5360-0649

\section{ARTICLE INFORMATION}

Received: 22 October 2021

Accepted: 10 November 2021

Published: 19 November 2021

DOI: 10.32996/jhsss.2021.3.11.6

\section{KEYWORDS}

Women, Covid-19, General

Community Quarantine, triple role

\section{ABSTRACT}

The Philippine government has imposed General Community Quarantine (GCQ) measures to slow the risk of the spread of COVID-19. This study seeks to identify the problems women encountered during this period and determine solutions to address those problems. Descriptive qualitative method multiple case study design was used. With thematic analysis, results found out that women are burdened by family security and financial capability, which contributes to the triple role of women. Moreover, resiliency has emerged as the main factor in solving these burdens. This study contributes to the fifth Sustainable Development Goal, gender equality, and women empowerment.

\section{Introduction}

This paper explores the experiences of women in a pandemic as inclined with the Sustainable and Development Goal about gender equality. I argue that in times of calamity like a pandemic, women become more vulnerable than men. Even before the pandemic, various scholars argued that women were poorer than men due to varied reasons (Schneebaum et al., 2018; Sierminska et al., 2010). This has worsened as shown by the Institute for Women's Policy Research data that among the total unemployed during the pandemic (from February to April) $55 \%$ of them were women. Losing a job means losing income which leaves women with fewer choices. Thus, women must not be left behind on disaster preparedness and mitigation.

This study seeks to answer the following question:

1. To identify the problems of women encountered;

2. To determine solutions to address problems with women encountered during the pandemic.

\section{Literature Review}

Women, especially mothers, tend to depend more on the reliefs given by the government rather than men. Moser (1993) reasoned that women in society have their triple roles: reproductive, productive, and community. These roles of women become a significant burden to them due to lockdown and quarantine measures. Lockdown and enhanced community quarantine limit people from going outside their homes. Thus, various establishments preferred to have a work from home scheme among their employees. Those businesses which were unable to adapt to the work from home schemes had temporarily closed, which resulted in unemployment in the various sector of the economy. Basic commodities such as food have undergone a drastic change since the transportation and logistics of these products have been barred because of the scare of transmission of the virus. People tend to panic buying grocery items and food products which results in a superficial shortage of commodities.

Mothers, as caretakers of the family (Moser, 1993), are bombarded by these growing concerns about the ability of the household to meet basic needs (Lobao \& Meyer, 1995). Various threats to income have risen such as possible loss of work of the head of household, inability to procure food items, and others.

Copyright: (c) 2021 the Author(s). This article is an open access article distributed under the terms and conditions of the Creative Commons Attribution (CC-BY) 4.0 license (https://creativecommons.org/licenses/by/4.0/). Published by Al-Kindi Centre for Research and Development, London, United Kingdom. 
As quarantine policies are implemented for safety measures against an outbreak, the individual capabilities of women are left unincorporated in policy-making. Nussbaum (2011) argued that government is responsible for ensuring the community's capability through the policies. Yet, there are certain quarantine/lockdown policies that restrict women especially mothers to be able to do something needed for their various roles. Unlike men, women are deprived and less privileged especially those living in rural areas. One example is the implementation of a quarantined pass that only one person is allowed to go outside per household. The name written on the quarantine pass is the only person allowed to go outside. Generally, those written on it are the head of the household which are usually the male gender, father of the family.

\section{Methodology}

This section of the study elaborates the research design, data collection method, data analysis, and ethical considerations.

\subsection{Research Design}

This study used the descriptive qualitative method, particularly the multiple case study design, to describe important experiences of numerous informants who had undergone the same phenomenon (Creswell, 2009). It is used to determine the dilemma faced by mothers during the disaster period at Digos City.

\subsection{Data Collection}

Purposive sampling was used to identify the informants who fit the defined characteristics of the focus of the research (Palinkas et al., 2015). This method was found suitable as samples may be based more on who is available and willing to participate in the indepth interview (Etikan, 2016). The in-depth interview was conducted via video conferencing. Video conferencing such as Zoom, Webinar, and Skype are just some of the many options available for face-to-face communication in real-time through technology. This method is now gaining traction in qualitative research for video conferencing interviews, especially during this pandemic crisis, where physical distancing is strictly implemented. This is much like a traditional interview, except the researchers and participants are simply in different locations. The research participants were mothers living in Digos City, Philippines.

\subsection{Data Analysis}

This study utilized a thematic analysis. Data gathered from the interview were transcribed and reviewed through thorough readings. The transcripts were coded to extract general meanings which contain words or phrases with coherent meanings. These were gathered regardless of the research question. Coded definitions related to the research question were grouped accordingly. Each interview had sets of clusters, and from these clusters, themes were extracted.

\subsection{Ethical Considerations}

The researchers were established and maintained the ethical standards throughout the study to prevent the falsification of data, thereby upholding the truth and pursuance of knowledge, which was the primary research goal. In this research study, autonomy was achieved through voluntary informed consent that was sent to the participants. Signed consent justified that the participants exercise their voluntary admission for full participation in this study. In establishing confidentiality, pseudonyms were used in all transcripts and letters to conceal the identity of the participants as part of the protocol of the study. During the interview process, privacy was respected by allowing the participants to decide when they would like the interview to be conducted. All qualitative data were adequately secured. Study participants were given a number code $(1,2$, and 3$)$, which appeared on the transcripts and file notes. All video recordings and file notes were saved in locked files.

\section{Results and Discussion}

There are five (5) qualitative studies presented about experiences of women during COVID-19 General Community Quarantine. This study gives importance to the expressed emotions of the informants and their sensitivity during an in-depth interview who answered on their free will. All of the informants worked in Digos City.

Three major objectives were shared with the informants and a series of interview guides and probing questions were asked from them with the expressed assurance of the confidentiality of their stories and whatever information gathered from them. The first research question is focused on the informants' experiences as women during the implementation of the GCQ as measures by the government to mitigate the spread of the pandemic. This includes the reasons for the decisions made, the influencing factors surrounding the situation they are in to and the problems encountered with the actions taken to resolve such difficulty. The research second question revolved around their coping mechanism to address the problems or challenges faced during GCQ.

\subsection{Case 1 - Annie}

Annie is a mother of a high school student. She recounts that during this time of pandemic every member of the household is all at home. Before the pandemic, all of them are not always at home due to having different activities to do. Now during the 
pandemic, they are all at home. She added that they need to work as one at home. Due to their difference in personalities, they oftentimes argue.

"Sa balay, it's a complete disaster... Naglisod mi ug adjust with each other"

(At home, it's a complete disaster...We have difficulties adjusting with each other

[behavior])

\subsection{Case 2 - Leny}

Leny is a mother of two children; One is a four-year-old girl and a one-year-old boy. Her children are left to the care of her family in rural areas to make sure that they are safe while Leny is working at Digos City. She conveys that being away from her children made her feel anxious but reiterated that she needs to be a way to enable her to feed her family and provide their necessities.

"Unlike before ba nga makasideline ka ug tudotudo. Diba katong mga sideline nga naa siyay mass gathering so nawala na siya"

(Unlike before, you can do various incomegenerating activities. Those sidelines that need mass gathering are prohibited.)

\subsection{Case 3 - Jasmine}

Jasmine is a mother of two kids. The eldest kid is on the elementary level and the youngest child does not go to school yet. Jasmine narrated that it was difficult during the pandemic since children need to stay at home and they get easily bored. They eat a lot while staying at home. They can't go to their friends. She added that expenses now are bigger because her kids are staying at home. She needs to wake up very early to cook breakfast and make sure that she won't come late to work. Her workplace is far from her home.

"Mas lisod siya kay ang mga bata man gud dapat dili jud kagawas. Mabored jud sila."

(It is more difficult nowadays because children should not go outside. They easily get bored.)

\subsection{Case 4 - Suzanne}

Suzanne is also a mother of two kids. The eldest kid is on the college level and the youngest child is on the high school level. She said that this pandemic brought some good points like lesser expenses because she no longer gives allowances to her children and she no longer needs to wake up very early to cook for her children. Their family no longer bonds outside but she still made sure that they bond at home, like getting take-out and eating together at home. Referring to her work, she mentions that it is difficult to advertise their services.

\section{"Lisod kaayo noh kay kung unsaon pagmarket ang among service."}

(It is a challenge on how we could market our

\subsection{Case 5 - Mae} service.)

Mae is a mother of a Grade 2 pupil. She enrolls her child in an online class. She worries about her child's use of technology since she can't always keep an eye on her child. While she went to work, her mother was the one caring for her child. She also added that due to a curb of income during the lockdown, she needs to be thick-faced and find other ways to generate additional income like selling online.

"Grabe kaayo. Makat-on nalang jud ka magpabaga ug nawong magsige ug post sa facebook unsa imong mga baligya "

(Too much. You will learn how to be thick-faced and constantly post your products on Facebook.) 


\section{Cross-Case Analysis}

The five (5) case studies that are described previously cover the life experiences of women during GCQ COVID-19. The in-depth interview was designed to answer the research questions for this study. For this part, cross-case analysis was conducted to compare the five case studies as to the similarities and differences of the situations. The commonalities and the uncommon perceptions, decisions, behaviors, and reactions of the informants as manifested in their stories are presented through themes and core ideas.

Table 1. Themes and core ideas on the experiences of women during COVID-19 GCQ measures.

\begin{tabular}{|l|l|}
\hline Major Themes & Core Ideas \\
\hline \multirow{5}{*}{ Family security } & Differences in personality among family members. \\
\cline { 2 - 2 } & Protect the family while providing for their needs. \\
\cline { 2 - 2 } & Children need more care and attention. \\
\cline { 2 - 2 } & Family needs to bond even in quarantine. \\
\cline { 2 - 2 } & Keeping safe the kids in all aspects. \\
\hline \multirow{5}{*}{ Financial capability } & Need to earn more to support family needs. \\
\cline { 2 - 2 } & Revenue-generating activities are restrained. \\
\cline { 2 - 2 } & Increased expenses for food. \\
\cline { 2 - 2 } & Opportunity to earn more lessens due to quarantine measures. \\
\cline { 2 - 2 } & Lesser income due to lockdown. \\
\hline
\end{tabular}

To answer the first objective, two major themes arise with five core ideas as shown in table 1 . These major themes are family security and financial capability. These two themes support the idea of (Moser, 1993) that women have triple roles. Two of these roles arise from the themes which are family security under the reproductive role and financial capability to productive role. Mothers always think about their family's well-being as further expounded by the core ideas of keeping safe the kids and the need to earn more to support the family. Furthermore, the second major theme, financial capability, and its five core ideas support the idea of Lobao \& Meyer (1995) stating that family financial matters affect mothers.

To address objective number two, only one theme floats and that is resiliency with 5 core ideas as shown in table 2 . Core ideas presented in Table 2 supports the idea of Nussbaum (2011) which is the person's ability 'to do and to be'. Even with restrictions due to the pandemic and they are not able to do things just like before with primary reasons of family in mind, mothers will become resilient to be able to provide for the family. Among these themes and core ideas, not once were mentioned the participant's dissatisfaction towards government policies in mitigating the health crises. Instead, participants are more focused on how to adapt to the existing health safety policies.

Table 2. Themes and core ideas on coping with these problems during the pandemic.

\begin{tabular}{|l|l|}
\hline Major Themes & Core Ideas \\
\hline \multirow{4}{*}{ Resiliency } & Be patient and creative. \\
\cline { 2 - 2 } & Follow government protocols and continue to find ways to provide for the family. \\
\cline { 2 - 2 } & Learn to adjust. \\
\cline { 2 - 2 } & Family bonding can be done even at home. \\
\cline { 2 - 2 } & Learn to find other ways to address the problems. \\
\hline
\end{tabular}

\section{Conclusion}

This study explores the problems encountered by women during the General Community Quarantine (GCQ) measures implemented by the Philippine government and seeks to find solutions to address their problems. The emerging themes that resulted from using thematic analysis are problems related to family security and financial capability. These two themes contribute to the triple role of women and suggest that during health crises bigger weights of problems are redirected to these two roles, where the burden of family security under the reproductive role, while the burden of financial capability under the productive role. Moreover, resiliency has surfaced as the main solution to adapt and address the burdens faced by mothers during the pandemic. The results generated from the participants did not relay any dissatisfaction towards the government-issued health safety policies. Instead, they accept and find ways how to continue their daily life within placed health protocol.

This study is relevant with the fifth Sustainable Development Goals (SDG) stating that we should "recognize and value unpaid care and domestic work and promote shared responsibility within the household and family" especially during this time of the pandemic, women specifically mothers have outstretched their heart in unquantifiable care for their family. 
This study is limited only to women mothers. Further research may be done with the other women's age groups and use other methods to deeply espouse the problems encountered by women during health crises and how they address their problems.

\section{References}

[1] Creswell, J. (2009). Research Design (3rd ed.). Sage Publication Inc.

[2] Etikan, I. (2016). Comparison of Convenience Sampling and Purposive Sampling. American Journal of Theoretical and Applied Statistics, 5(1), 1. https://doi.org/10.11648/j.ajtas.20160501.11

[3] Lobao, L., \& Meyer, K. (1995). Economic decline, gender, and labor flexibility in family-based enterprises: Midwestern farming in the 1980s ProQuest. Social Forces; Oxford, 74(2), 575. http://dx.doi.org/10.1093/sf/74.2.575

[4] Moser, C. (1993). Gender planning and development: Theory, practice, and training. https://search.proquest.com

[5] Nussbaum, M. C. (2011). Creating Capabilities. Harvard University Press.

[6] Schneebaum, A., Rehm, M., Mader, K., \& Hollan, K. (2018). The Gender Wealth Gap Across European Countries. Review of Income and Wealth, 64(2), 295-331. https://doi.org/10.1111/roiw.12281

[7] Sierminska, E. M., Frick, J. R., \& Grabka, M. M. (2010). Examining the gender wealth gap. Oxford Economic Papers, 62(4), 669-690. https://doi.org/10.1093/oep/gpq007 